\title{
HOMENAGEM TOPONÍMICA A NINA RODRIGUES NO ESTADO DO MARANHÃO: APOLOGIA IMPLÍCITA À CRENÇA NA DEGENERESCÊNCIA ÉTNICA PELA MESTIÇAGEM?
}

Toponymic Tribute to Nina Rodrigues in the State of Maranhão: An Implicit Apology to the Myth of The Ethnic Degeneration By Human Interbreeding?

Homenaje Toponímica a Nina Rodrigues en el Estado de Maranhão: Disculpa Implícita al mito de la Degeneración Étnica por el Mestizaje Humano?

\section{Reginaldo Nascimento Neto ${ }^{* 1}$}

${ }^{1}$ Doutorando pela UFT - Universidade Federal Tocantins, PPGL - Programa de Pós-Graduação em Letras, Araguaína, Tocantins, Brasil.

*Correspondência: Rua Sigma, 310, São Luís - MA, Brasil. CEP:65070-55077.010-090. e-mail nadynhu@ifma.edu.br.

\section{RESUMO}

O objetivo deste artigo é perscrutar se a homenagem toponímica a Raimundo Nina Rodrigues, no Estado do Maranhão, advoga implicitamente o mito, sedimentado pela frenologia, de que a mestiçagem humana produz degenerescência étnica, conforme postulava esse médico brasileiro (1862-1906), arvorando-se no pressuposto da superioridade da etnia branca (SKIDMORE, 1989). Trata-se de uma investigação de cunho bibliográfico e fundamenta-se nos estudos de (CLOVAL, 2001), (NASH, 2013) e (DICK, 1987, 1990). À princípio, pretende-se demonstrar que as teses racistas do Dr. Nina Rodrigues, claramente descortinadas por meio do vocabulário que ele emprega, são oriundas de um contexto histórico modelado pelo Darwinismo Social da Europa e pela ideologia escravagista mantida no Brasil mesmo após 1888. Esse paradigma deveria ser rechaçado à luz das descobertas antropológicas de mais amplo espectro que se tem presentemente. Para tanto, partindo-se de postulados sobre a origem da etnia negra, seus etnônimos e atuação na civilização antiga, chega-se à ilação de que, a deseducação, o tratamento cruel e a constante depreciação procedentes de diversos formadores de opinião social engendram comportamentos e as ditas taras hereditárias degenerativas, isto é, não se trata de índole imanentemente selvagem, mas produto.

Palavras-chave: Toponímia, Nina Rodrigues, etnia.

\section{ABSTRACT}

This paper purpose is to peer if the toponymic tribute to Nina Rodrigues in the state of Maranhão advocates implicitly the myth sedimented by Phrenology that human interbreeding produces ethnic degeneration, as this Brazilian physician(1862-1906) used to postulate flying on the assumption of a superiority of the white ethnicity. (SKIDMORE, 1989). This is a bibliographic search and it is anchored on the studies of (CLOVAL, 2001), (NASH, 2013) e (DICK, 1987, 1990). In the beginning, it intends to show that the racist theses of Dr. Nina Rodrigues, clearly unveiled by means of the vocabulary he employs, are arising from a historic context carved out by the European Social Darwinism and the slaveholder ideology, maintained in Brazil, even after 1888, and, that such a paradigm should be rejected at the light of the highest spectrum anthropological discoveries existent today. So, 
starting from postulates about the negro ethnicity origin, their ethnonyms and acts in the old civilization, it touches the illation that miseducation, cruel treatment, and constant depreciation, coming from several makers of social opinion, build behaviors and the said hereditary degenerative defects, i/o it is not an immanently wild nature, but a product.

Keywords: Toponymy, Nina Rodrigues, ethnicity. Up to three words.

\section{RESUMEN}

En este artículo se propone investigar si el tributo toponímica Raimundo Nina Rodrigues, en el estado de Maranhão, implícitamente aboga por el mito, sedimentado por la frenología, que el entrecruzamiento humano produce la degeneración étnica, tal como postula que médico brasileño (1862-1906), arvorando- en la superioridad de la raza blanca de la asunción (SKIDMORE, 1989). Esta es una naturaleza bibliográfica de la investigación y se basa en estudios de (CLOVAL, 2001), (NASH, 2013) Y (DICK, 1987, 1990). En primer lugar, tenemos la intención de demostrar que las tesis racistas del Dr. Nina Rodrigues, descortinadas claramente a través del vocabulario que utiliza, venimos de un contexto histórico modelado por el darwinismo social de Europa y la ideología de esclavos que tuvo lugar en Brasil, incluso después de 1888. Este paradigma debe ser rechazada a la luz de los descubrimientos antropológicos espectro más amplio que tiene actualmente. Por lo tanto, a partir de las hipótesis sobre el origen de la raza negro, sus gentilicios y el rendimiento en la civilización antigua, uno llega a la conclusión de que el tratamiento cruel sin educación y la depreciación constante vinieron de otros entrenadores opinión comportamiento social engendran y dichos defectos hereditarios degenerativos, es decir, que no es inmanente naturaleza salvaje, pero en el producto.

Descriptores: Toponimia, Nina Rodrigues, el origen étnico

\section{INTRODUÇÃO}

O estabelecimento em um território vem inexoravelmente acompanhado não só de ideais, mas também da cultura e da ideologia de que o homem está imbuído. A tentativa de institucionalizar, homenagear, simbolizar e eternizar sua linguagem, costumes, valores, cosmovisão, sentimento de propriedade e, ou a ortodoxia que tem a respeito de si mesmo passa a ser sua motivação onomástica para esse lugar.

O termo Onomástica é oriundo do radical

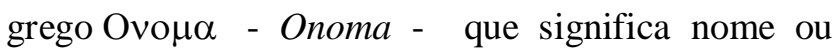
fama, empregado nas palavras onomatopeia, genoma, metonímia entre outras.

Onoma era usado para designar tudo que um nome engloba - todo pensamento ou sentimento que vem à mente quando mencionado, lembrado ou ouvido. Assim, é derivativo presumido da autoridade ou caráter de quem respectivamente defere ou recebe o nome.
(VASCONCELOS, 1931, p.3) chama a Onomatologia de o ramo da Glotologia que estuda os nomes próprios e, a divide em três partes: a Antroponímia, composta pelos radicais gregos $\alpha \nu \tau \rho \circ \pi \circ \sigma$ (antropós) que significa homem ou gênero humano, e vouoo (nomós) para nome. Isto é, $o$ estudo dos nomes individuais, com o dos sobrenomes e apelidos; a Toponímia, palavra

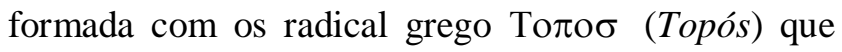
significa lugar, em Português tem-se esse radical em topografia, tópico, utópico, portanto, o estudo dos nomes de sítios, povoações, nações, e bem assim de rios, montes, vales, etc., - isto é, os nomes geográficos. A última divisão desse autor, abrange os outros nomes não abraçados pelas duas classes precedentes, como entidades sobrenaturais, astros, ventos, animais, ou coisas, posteriormente detalhada por (DICK, 1990).

Segundo (FURTADO, 1960, p.8) os topônimos balizam, definem e delimitam uma área 
cultural, e chega a declarar que eles representam a própria alma do país e da raça.

Para ele, a Toponímia não é somente etimológica, e emprega metáforas para designá-la como um dos instrumentos que permitem atingir as camadas mais antigas da língua, sendo, portanto, fósseis linguísticos que indicam e refletem os estratos das línguas faladas anteriormente naquele lugar, e a fisionomia de um país.

Todavia, um topônimo, conforme (NASH, 2013, p.11), envolve lidar com o mundo exterior e considera as relações externas ao sistema linguístico porque a toponímia e os processos de nomeação são motivados, isto é, intencionais.

Também na perspectiva da intencionalidade, (CLOVAL, 2001, p.189) desmistifica a inocente concepção cartográfica de que nomes geográficos são de interesse do cartógrafo, pois são necessários para a identificação de lugares e características simbolizadas nos mapas. É virtualmente impossível referir lugares específicos nos mapas sem empregar os nomes dos lugares (ERWIN RAISZ, 1948, apud FURTADO, 1961, p. 7), quando afirma:

\begin{abstract}
A Toponímia é uma herança preciosa das culturas passadas. Batizar as costas e as baías das regiões litorâneas foi a primeira tarefa dos descobridores [...] o batismo dos espaços e de todos os pontos importantes não é feito somente para ajudar uns aos outros a se referenciar. Trata-se de uma verdadeira tomada de posse (simbólica ou real) do espaço. (CLOVAL, 2001, p.189).
\end{abstract}

Como segue, é marcantemente interessante o que (NASH, 2013) declara sobre a conversão do espaço em lugar pela apropriação cultural e linguística outorgando a ele um caráter topofílico:

\footnotetext{
A Toponímia também mostra como o espaço se torna lugar por meio da apropriação cultural e linguística, bem como os humanos inventam e continuamente reinventam e recriam o lugar através do processo e prática de nomear (NASH, 2013, 11).
}

Dessa forma, na base ou etiologia de um topônimo está fossilizada a inscrição da ideologia, crenças, história, geografia e filosofia que o motivaram e conferiram identidade. Portanto, o estudo da toponímia pode desvelar as influências exercidas pelo poder em voga para a nomeação de um dado lugar e, descortinar as inferências de glamour e publicidade da filosofia que gera esse nome.

Como um invólucro que envelopa o proselitismo das motivações onomásticas, o topônimo passa a ser uma porta de investigação histórica, geográfica, política e social por causa dos dados nele incrustados. (DICK, 1990) assim se expressa:

(...) os topônimos se apresentam (...) como importantes fatores de comunicação, permitindo, de modo plausível, a referência da entidade por eles designada. Verdadeiros "testemunhos históricos" de fatos e ocorrências registrados nos mais diversos momentos da vida de uma população, encerram, em si, um valor que transcende ao próprio ato de nomeação: se a Toponímia situa-se como a crônica de um povo, gravando o presente para o conhecimento das gerações futuras, o topônimo é o instrumento dessa projeção temporal. (DICK, 1990, p. 21-22).

Ainda segundo (DICK, 1987, p.83) o surgimento da onomástica como epistemologia se dá na França por volta de 1878 com August Longnon que, ministrou aulas sobre suas pesquisas sobre toponímia na École Pratique de Hauste Études e, à semelhança de Sausure, teve seus estudos Les Noms de Lieux de la France publicados postumamente por seus alunos em 1912.

No Brasil, a organização de sua Toponímia é oriunda da fundação do IBGE - Instituto Brasileiro de Geografia e Estatística - que propôs o Decreto-Lei 311 sancionado em 02 de Março de 1938, que trata sobre a divisão territorial do Brasil. 
Segundo (CARVALHINHOS, 2016), Como disciplina, a Toponímia surgiu em 1934 na Universidade de São Paulo - USP, com o projeto do professor de Etnografia e línguas Tupi Guarani Plínio Ayrosa, enquanto buscava uma nova abordagem para o ensino de Geografia, História e Etnografia. Enquanto se estudava o léxico indígena, percebeu-se que o estudo linguístico seria indissociável dos estudos toponímicos. Dessa forma, a disciplina de toponímia começa a tomar os moldes atuais na década de 1960, quando o curso de Letras foi reformulado.

\section{MATERIAIS E MÉTODOS}

Este trabalho desenvolveu-se por meio de investigação bibliográfica e documental relacionada com a revolta da balaiada e com a vida e escritos de Nina Rodrigues. Objetivou-se cruzar as ideias desse médico maranhense com as descobertas de historiadores na busca de possíveis razões para a homenagem toponímica à Nina Rodrigues.

\section{RESULTADOS E DISCUSSÃO}

\section{Toponímia Do Maranhão}

Sendo uma das vinte e sete Unidades Federativas da União (UF), o Maranhão possui 217 municípios e é o segundo maior estado da Região Nordeste. Sua capital e mais populosa cidade é São Luís.

Conforme (TIBIRIÇÁ, 1985, p.84), a etimologia do nome Maranhão deriva do Tupi Mbarã-nhana, pará-nhana, e significa "rio que corre". Para SAMPAIO, 1987, p.280), é oriunda de Mbará-nhã, e significa o mar corrente; o grande caudal que simula o mar a correr.

A região que hoje compreende o estado do Maranhão, havia sido no ano de 1535 dividida em duas capitanias hereditárias pelo Rei Dom João III.
No entanto, em 1612, os franceses se estabeleceram ali até 1615. Nesse ano, os portugueses, sob a liderança de Jerônimo de Albuquerque, os expulsaram. Porém, foi no ano de 1621 que foi instituído o estado do Maranhão e Grão-Pará. O desmembramento com o Grão-Pará se deu em 1774.

Quando o Brasil foi descoberto, o Maranhão era povoado por diversas tribos indígenas, como os tupis, Jês, Guajajaras, Urubus. Muitos povos indígenas do Piauí, entraram no Maranhão com o propósito de fugir da captura dos brancos. É possível notar que muitos topônimos do estado do Maranhão têm origem indígena, como Arari, Buriti, Cajari, Itinga, Peri-mirim, e outros.

Os primeiros levantamentos toponímicos minuciosos sobre a capital do Maranhão se deram por meio da pesquisa de Domingos Vieira Filho, intitulada Breve história das ruas e praças de são Luís. (VIEIRA FILHO, 1971). Depois desses estudos, a Lei n. 2.151 de 04 de fevereiro de 1975 nomeou a CPT - Comissão Permanente de Toponímia do Município de São Luís e dispôs sobre as normas para a nomeação de lugares da capital a serem observadas. Porém, resumiu-se à capital do Estado. A Lei 4.669 de 11 Outubro 2006, que tratou do plano diretório do município de São Luís, tomando providências na seção XIV Título XI e no art. 164, para que a lei municipal de toponímia fosse revisada pelo poder público no prazo de três anos a partir da aprovação do plano diretor, excetuando os bairros cuja definição dos limites dependesse de normas legais estaduais.

\section{O Município De Nina Rodrigues}

De acordo com o Instituto Brasileiro de Geografia e Estatística - (IBGE), dos 217 municípios do estado do Maranhão, a cidade de Nina Rodrigues teve sua formação em um lugar chamado Fortaleza, 
uma manga ${ }^{1}$ única para boiadas que rumavam à Icatu ou morros. Em consonância com o IBGE, foi elevado à categoria de município pela Lei 2183 de 30-12-1961 após desmembramento da cidade de Vargem Grande.

Em 1835, o povoamento dessa área formou a Vila da Manga do Iguará. Cinco anos depois, mesmo sendo ainda um pequeno povoado, alojou uma parte das tropas do Cel. Luís Alves de Lima e Silva durante a repressão da revolta conhecida como Balaiada.

A vila é denominada de Vargem Grande pela resolução datada de 19.04.1833, após o desmembramento de Itapecuru-Mirim, porém, o decreto 539 de 16.12.1933 extingue esse município, que só se eleva novamente à categoria e município em 15.05.1935.

\section{Contexto Da Balaiada}

Como já citada acima, a Revolta da Balaiada, conforme (JANOTTI, 1987), e (SANTOS, 1983), ocorreu entre os anos de 1838 e 1841, e teve como palco o povoado de Vila a Manga do Iguará.

Havia rivalidade entre grande parte da população pobre do Estado e o monopólio político dos fazendeiros dessa região, que empregavam de violência para salvaguardar seus interesses econômicos.

Uma Boiada pertencente ao Padre da cidade de Arari e conduzida pelo vaqueiro Raimundo Gomes foi apreendida pelo subprefeito de Vila da Manga do Iguará, que tinha desafetos com esse Pároco. Os vaqueiros e um irmão de Raimundo Gomes foram presos. Este irmão de Raimundo Gomes consegue fugir e toma a cadeia de assalto libertando todos os prisioneiros e iniciando assim, uma resistência armada contra o Governo da Província.

\footnotetext{
1 Manga é a denominação dada a um corredor estreito ladeado por paredes naturais de varas usado para a passagem de gado.
}

Tropas foram enviadas para combatê-los. Uma dessas tropas invadiu a casa de Francisco dos Anjos - apelidado de Balaio, dado seu ofício de fabricá-los - e, violentou suas filhas. Revoltado com essa barbárie, o Balaio conseguiu realizar um levante da massa de moradores dos sertões, tornando-se, junto com o Negro Cosme, um dos líderes da Revolução.

Em 1839, os Balaios, - seguidores de Balaio - conquistaram a vila Caxias. O Governo Maranhense organizou forças militares para combater os Balaios, que já contavam com a participação de muitos escravos fugitivos, e trabalhadores pobre da região.

O Cel. Luís Alves Lima e Silva, posteriormente conhecido como Duque de Caxias, reconquistou essa vila. Depois de perder a vila de Caxias e a morte de seus líderes, o movimento se enfraqueceu. O líder e ex-escravo Negro Cosme Bento foi capturado em 1841, pondo fim à Revolta da Balaiada.

\section{As Ideias De Nina Rodrigues}

Vinte e um anos depois, em 1862, nascem na região da manga - lugar que, em 1935 voltaria a ser o município de Vargem Grande - Raimundo Nina Rodrigues, médico, patologista e etnógrafo, que conquistou renome internacional e é considerado o pai da antropologia criminal no Brasil, porém, arvorando-se em teses racistas. (Skidmore, 1989; Stefano, 2001).

O maranhense Raimundo Nina Rodrigues era filho de um coronel latifundiário chamado Francisco Solano Rodrigues e de Luíza rosa Nina Rodrigues. Ela, conforme Correia (1998, p. 314), era descendente de judeus que fugiram para o Maranhão em consequência das perseguições antissemíticas na Península Ibérica. Nina Rodrigues teve uma babá mulata. Formou-se na faculdade de Medicina em 
1886, e em 1887, defendeu sua tese doutoral intitulada As Amiatrofias de Origem Periférica. (Correia, 1998, p. 321).

Figura 1. Dr. Raimundo Nina Rodrigues - 1862-1906

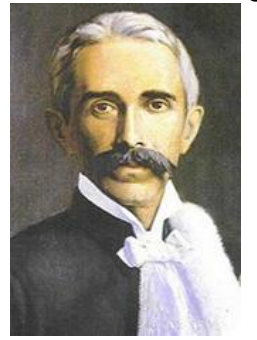

Fonte: https://pt.wikipedia.org/wiki/Nina_Rodrigues acessado em 07 de Agosto de 2016 8:45

Dedicou-se então ao exercício da medicina em São Luís do Maranhão, e publicou periódicos médicos sobre higiene e lepra. Os assuntos sobre os quais escreveu eram a mestiçagem no Brasil, classificação racial da população brasileira, antropologia criminal, e frenologia - termo tratado mais adiante.

$\mathrm{O}$ autor postulava sobre fatores raciais como predisposição ao crime e, conforme (NEVES, 2008), era racista pois defendeu a relação de superioridade e inferioridade de algumas raças em detrimento de outras. Em seus trabalhos, Nina Rodrigues denominavam de mulatos os filhos gerados do cruzamento entre portugueses e africanas, classificando-os de mulatos de primeiro sangue, mulatos claros e mulatos escuros. (RODRIGUES, [1894], 1993, p. 91).

No que se refere à etimologia da palavra mulato, é consenso de que ela deriva de mula, nome dado a um animal híbrido e estéril gerado pelo cruzamento entre um cavalo com uma jumenta, no intento de comparar uma mistura de homem branco com mulher negra ou vice-versa como declara (BUENO, 2003), (HOUAISS, 2004), e outros.

Nesses trabalhos, apresentou os mamelucos como resultado da mistura entre branco e índia. Os mamelucos, classificou-os como mais próximos aos brancos. Caboclos eram mestiços de puro sangue. (RODRIGUES, 1894). Do negro com o índio, resultariam os cafuzos.

(AYROSA, 1937, p. 163-166) declara que o termo mameluco, no Brasil, designou sempre o mestiço, filho de pai europeu e mãe índia.

Quanto à etimologia no entanto, esse autor, sugere uma controvérsia: se mameluco é o termo árabe oriundo de mamlouk significando governar, possuir, ter sob ordens, etc, e equivaleria a servus em latim, ou de mamãrúca, que se decompõe em mamã, (misturar, mesclar) e rúca ou yrúca (tirar, extrair), isto é, aquele que procede da mistura?

Nesse contexto, Nina Rodrigues tinha o pensamento de que a mestiçagem humana era um problema biológico, (RODRIGUES, 2008, p.1151) e um risco à pureza dos brancos.

Ao brasileiro mais descuidado e imprevidente não pode deixar de impressionar a possibilidade da oposição futura, que já se deixa entrever, entre uma nação branca, forte e poderosa, provavelmente de origem teutônica, que se está constituindo nos estados do Sul, donde o clima e a civilização eliminarão a Raça Negra[...] O mestiçamento não faz mais do que retardar a eliminação do sangue branco. Esta eliminação, que, na raça pura de mescla, se processa em poucas gerações, pela degenerescência de marcha aguda a que se referia Rijckevorsel a propósito dos Europeus do Norte, tem lugar, mal grado o cruzamento, apenas com a diferença de efetuar-se gradualmente por um processo degenerativo de marcha crônica e, portanto muito lenta. (RODRIGUES, 1935).

\section{A Influência Do Darwinismo Social Em Nina} Rodrigues

Nina Rodrigues foi efetivamente contaminado pelas ideias do Darwinismo Social, ideologia corrente em seu tempo e oriunda do Reino Unido na década de 1870.

Durante o período da Revolução Comercial, a Inglaterra acumulou mais capital que todas as nações 
vizinhas por causa do monopólio que exercia sobre o tráfico de escravos, à expansão comercial de seus produtos de lã, e também devido aos cercamentos e apropriações indébitas das terras dos camponeses pelos latifundiários. Expropriados de suas terras, os camponeses rumaram para as cidades a fim de vender sua mão-de-obra para a indústria $a b$ ovo.

Os camponeses ficaram reduzidos à miséria, o que era condição sine qua non para o aumento da riqueza da indústria capitalista. Essa circunstância favoreceu o surgimento da Revolução Industrial, além do advento das máquinas ferramentais, que operou mudanças significativas nos meios de produção, pois a máquina é mais resistente, e põe em operação um número muito superior de procedimentos ao mesmo tempo, que o homem, e eleva a produção a uma escala incomparavelmente superior à do trabalhador manual, artesanal.

Tal condição tornou ainda mais desvalorizada a mão-de-obra já miserável do camponês, como descrevem respectivamente (GORKI, 1982) e (SCHNERB, 1961):

Todos os dias, o apito pungente da fábrica cortava o ar esfumaçado e pegajoso que envolvia o bairro operário e, obedientes ao chamado, seres sombrios, de músculos ainda cansados, deixavam seus casebres, acanhados e escuros, feito baratas assustadas. Sob o frio amanhecer, seguiam pela rua esburacada em direção às enormes jaulas de pedra da fábrica que os aguardava desdenhosamente (...) vozes sonolentas emitiam roucas saudações, palavrões dilaceravam, raivosamente, o ar. Mas eram diferentes os sons que acolhiam os operários: pesadas máquinas em funcionamento, o resfolegar do vapor (...) o dia consumia-se na fábrica, suas máquinas sugavam de seus músculos toda a energia de que necessitavam. Mais um dia irremediavelmente riscado de suas vidas. (GORKI, 1982).

...nós é que somos chamados a canalha. Estamos fartos, estamos fatigados, morremos de fome, não aguentamos mais. É melhor que desapareça nossa carcaça; junto com nossos filhos e filhas. É nossa a mortalha que tecemos. (SCHNERB, 1961).

A Revolução Industrial do século XVIII acirrou a divisão entre o proletariado e a burguesia, bem como o predadorismo deste último, criando uma sociedade em que o mais forte sobrevive, e o caráter de exploração se tornou convencional e paradigmático.

Os óbvios problemas emergentes dessa situação, como superpopulação, miséria, epidemias, falta de higiene e possível revolta das massas preocupavam os economistas da Europa no século XVIII. Decorre daí que, a obra de Thomas Malthus (1766-1834) Um Ensaio sobre o Princípio da População - (An Essay on the Principle of Population) - publicado em 1798, vem ao encontro dessas apreensões, afirmando que a população do mundo crescia em progressão geométrica - fator multiplicado por uma razão - enquanto a produção de comida crescia em progressão aritmética - fator somado a uma razão. Portanto, supostamente, a população cresceria muito mais do que a produção de alimentos, desencadeando em uma miséria permanente.

Influenciado pela obra de Malthus, (DARWIN, 2009, p.30, 75 e MAYR, 1982), Charles Robert Darwin (1809 - 1882) concebeu que a luta pela sobrevivência perpetuaria aos mais adaptados ao ambiente e descartaria aos menos especializados, isto, em suas observações, representaria que as variações vantajosas seriam perpetuadas. Em consequência disso, escreve A origem das Espécies através da seleção natural ou a preservação das raças favorecidas na luta pela sobrevivência - (On the Origin of Species by Means of Natural Selection, or The Preservation of Favoured Races in the Struggle for Life) - em 1859.

Nessa obra, ele teoriza que, supostamente, todos os seres vivos evoluíram, isto é, passaram por processo de diversificação ao longo do tempo, dando origem às novas espécies atuais ou já extintas na Terra por meio de mutações. No entanto, isso se deu antes das descobertas da Genética moderna e de 
Louis Pasteur. Falando sobre mutações capazes de gerar novas espécies, (SIMPSON, 1953), assim se manifesta quanto ao Darwinismo:

A menos que exista algum fator aumentando tremendamente a chance de mutações simultâneas, tal processo jamais ocorreu na natureza" (SIMPSON, 1953, p. 96).

Todavia, as ideias de liberalismo econômico, concorrência, capitalismo, sobrevivência do mais apto geraram condições favoráveis à aceitação de sua teoria, isto é, sua teoria encontrava eco no contexto social da época. O princípio do laissez-faire - ou deixar fazer - protagoniza que o egoísmo equilibra, isto é, após a eliminação dos ineficientes, a nação se harmoniza. (GOULD, 1979). Ao falar sobre castas de formigas obreiras estéreis em associação com a seleção natural econômica, (DARWIN, 2009) escreveu:

Acredito que acabo de explicar como se originou o maravilhoso facto da coexistência no mesmo formigueiro de duas castas claramente definidas de obreiras estéreis, que diferem tanto umas das outras, como dos seus progenitores. Podemos ver quão útil a sua produção pode ter sido para uma comunidade social de formigas, pelo mesmo princípio que diz que a divisão do trabalho é útil ao homem civilizado. (DARWIN, 2009, p. 238).

Portanto, essa premissa de estratificação racial para o trabalho pode ter contribuído amplamente na sedimentação do Darwinismo Social, uma teoria que tenta, conforme (CLAEYS, 2000), justificar a política do liberalismo sob o conceito de que seria natural a sobrevivência do mais forte.

\section{A Frenologia e a Eugenia}

Somado a essa conjuntura, eclode a pseudociência batizada de Frenologia com o médico alemão Franz Joseph Gall (1758-1828), o primeiro neuroanatomista a estudar a localização das funções cerebrais, que desencadeou a cranioscopia e posteriormente foi chamada de Frenologia do grego $\phi \rho \varepsilon v o \sigma-$ phrenos $=$ mente $+\lambda o \gamma o \sigma-\operatorname{logos}$ = estudo.

A proposta era adivinhar as propensões de caráter, personalidade e nível do desenvolvimento das faculdades mentais e morais de um indivíduo por meio da aparência e dos medimentos do crânio humano. Para eles, essas faculdades estariam localizadas em setores cerebrais locados na superfície do crânio e supostamente poderiam ser interpretados pelo exame. Esses setores afetariam o contorno do crânio.

A frenologia sustentava assim que a forma da cabeça de uma pessoa determinava o seu caráter e personalidade bem como propensão para o crime. Embora baseada em uma premissa falaciosa, foi amplamente aceita como autêntica na época.

Uma escritora americana chamada Ellen White (1827-1915) foi uma das penas a se opor a essa modalidade. Em 1893, escreveu sobre a frenologia como "vã filosofia, se gloriando em coisas que não entendem, pressupondo um conhecimento da natureza humana que é falso". (WHITE, 1893).

No entanto, grande era o número de publicações sobre esse assunto. Uma dessas obras era O manual de cura pela água - The water cure manual- com 284 páginas e apresentava uma lista de sessenta e cinco livros sobre saúde física e mental, dentre as quais vinte e três versavam sobre frenologia. Foi publicado por Fowler Brothers e Samuel Wells, bem como o Jornal Frenológico Americano e vida ilustrada - American Phrenological Journal and Life Illustrated ativo de 1838 a 1911.

Todos esses elementos populares no século XVIII, geraram grande controvérsias pois foram muitas vezes usados para promover e justificar o racismo de forma aparentemente científica. A Frenologia lançou os alicerces para a ereção da Eugenia $(\varepsilon v-\mathrm{eu}=$ bom $+\gamma \varepsilon v \varepsilon-$ gene $=$ geração $)$, 
termo criado em 1883 para designar o estudo de agentes que melhorariam ou empobreceriam qualidades raciais das futuras gerações, isto é, redundava em concepções de purificação da raça humana.

O contexto ora descrito acima, influenciou a formação ideológica e concepções de Nina Rodrigues.

Como visto anteriormente, sua mãe era descendente de Judeus egressos pela fuga da intolerância europeia, e os conceitos racistas postulados e advogados por Nina Rodrigues como a Eugenia e o Darwinismo social tornam-se baldrames da visão Nazista desencadeou o holocausto durante a Segunda Guerra Mundial, quando mais de seis milhões de judeus, isto é, a etnia do próprio Nina Rodrigues, foram exterminados em campos de concentração e câmaras de gás.

\section{Paradigma E Responsabilidade Individual}

É possível entender a força que o paradigma exerce nos modos de ver o mundo quando se considera, conforme (DURKHEIM, 1978), que " $a$ sociedade é um organismo exterior e maior que os indivíduos" e, dessa forma, "a relação entre os indivíduos e a coletividade", supõe-se também a científica, "é o estabelecimento do consenso harmônico" em uma "consciência coletiva" que é uma normatização geral do comportamento e forma de pensar dos indivíduos, pois, "o pensamento das pessoas é moldado pelo que lhes é ensinado”. Podese assim dizer que, o paradigma de uma época é um “adestrador dos indivíduos".

O homem que a educação deve realizar em cada um de nós, não é o homem que a natureza fez, mas o homem que a sociedade quer que ele seja; $\mathrm{e}$ ela o quer conforme o reclame a sua economia interna, o seu equilíbrio. (DURKHEIM, 1978, p. $115)$.
Nessa mesma linha de pensamento, (MORIN, 2006, p. 10) adverte que paradigmas são "princípios ocultos que governam nossa visão das coisas e do mundo sem que tenhamos consciência disso”. Também (MARCUSCHI, 2007, p. 83) defende que " cultura, sociedade e cognição estão na base de toda nossa capacidade de pensar e dizer o mundo", (negrito meu) e, (BOURDIEU, 2005) fala em "internalizações implícitas", usando expressões como: "esquemas de pensamento insconsciente", "internalizações não explicitadas" e "afinidades subterrâneas" para caracterizar o que pode ser entendido como paradigma de uma época:

Assim, em cada época de cada sociedade, há uma hierarquia dos objetos de estudo legítimos que consegue impor-se de maneira tanto mais total por não haver necessidade de ser explicitada uma vez que ela aparece como se tivesse depositada nos instrumentos de pensamento que os indivíduos recebem no curso de sua aprendizagem intelectual [...] as afinidades subterrâneas que unem as obras humanas encontram seu princípio na instituição escolar investida da função de transmitir conscientemente (e também, em certa medida, inconscientemente) o inconsciente, ou melhor, de produzir indivíduos dotados deste sistema de esquemas inconscientes (ou profundamente internalizados) que constitui sua cultura." (BOURDIEU, 2005, p. 211- 213) (negritos meus).

Nessa perspectiva, (BAKHTIN, 2006, p. 47) diz que "a consciência constitui um fato sócioideológico" e que "os processos que determinam o conteúdo do psiquismo não se desenvolvem no organismo, mas fora dele”, dessa forma, “os fatores sociais determinam a vida concreta de um dado indivíduo, nas condições do meio social."

Também assim acredita (WILLIAMS, 1979) quando declara que:

A sociedade não é apenas a casca morta que limita a realização social e individual. É sempre um processo constitutivo com pressões muito poderosas que são internalizadas e se tornam vontades individuais. (WILLIAMS,1979, p. 91). 
Além de entender a força que o paradigma exerce nos modos de ver o mundo, urge também perceber que cada paradigma traz consequências inexoráveis.

O exemplo que se pode mencionar na história sobre as consequências de uma cosmovisão de épocas equivocada, foi a ação de Hitler (1889-1945), durante a Segunda Guerra Mundial (1939-1945), protagonizando o holocausto de mais de seis milhões de judeus em campos de concentração, câmaras de gás e tumbas coletivas.

O paradigma antropocentrista emergente após a publicação de A Origem das Espécies (1859) por Charles Darwin (1809-1882) apresentou observações de que na natureza, há a lei do mais forte, isto é, o mais apto sobrevive e as espécies estão em evolução. Hitler então poderia ter postulado que o povo ariano estava em estágios mais desenvolvidos na evolução e que, etnias como a dos Judeus, negros, ou não alemães, deveriam ser extirpados a fim de auxiliar a natureza em sua tarefa da seleção do mais apto.

Observe-se que, nessa concepção, se é natural ao mais forte sobreviver e devorar ao mais fraco, então, Hitler, ao invés de genocida, não seria apenas mais uma vítima do paradigma? O egoísmo, a falta de solidariedade, o individualismo e a devastação ambiental não seriam naturais também? Claro que não.

Aparentemente torna-se bastante cômoda a ideia de que, se os indivíduos são fruto da formulação social e que seus pontos de vista, modo de pensar, juízos de valor e arbítrios são cunhados em uma bitola também feita pelo social, então, não restariam responsabilidades para o indivíduo diante de suas escolhas e ações.

Poder-se-ia facilmente afirmar que o espírito da época é que é o responsável supremo pelos erros ou acertos, crimes ou benfeitorias, guerras ou acordos de paz.
Isso inocentaria a todos, e faria da humanidade toda um bando de bonecos programados para funcionar dentro da saga determinista ficcional de matrix. Talvez, esse era o sentimento percebido por Fiódor Dostoiévski em seus companheiros na prisão na Sibéria onde ficara preso na década de 1840 por subversão ao afirmar: "No periodo de vários anos, nunca vi sinal algum de arrependimento entre essas pessoas, e nenhum vestígio de pensamento triste em relação a seus crimes, e a maioria delas no intimo se considerava absolutamente certa." (FRANK, 1999 )

Não se pode ignorar que há imanentemente na estrutura do pensamento humano um tino ou consciência primordial questionadora do espírito da época. Assim como nos estudos de Freud (18561939) e Lacan (1901-1981), asserta-se que há um $I d$, Ego e Superego a equilibrar as decisões do indivíduo, é, portanto, de se supor que assim também se dê na esfera das percepções de costumes e status quo sociais da época discrepantes com o ideal.

Se assim não fosse, a sociedade estaria fadada à estagnação. Mas, (THOMPSON E WILLIAM, 1979) tratam do movimento que impulsiona a sociedade adiante dos paradigmas, ao tratar do estudo das artes. Para eles, o sentimento de uma época se desloca de seu aspecto dominante para o residual e emergente sendo construído, resignificado, e veiculado no sentido de fugir da cela do pensamento, e concluem que o artista normalmente vislumbra mais facilmente o emergente e opta por ele.

Quando (RODRIGUES, 2008) emprega lexias $^{2}$ como mestiçagem, problema, animais, decadência, degenerescência, padece, indolência, primitivos, selvagem, tara, atormentada, monstro, inferior, produto desequilibrado, raça superior, pura,

\footnotetext{
${ }^{2}$ Entenda-se lexia como formas que aparecem no discurso conforme Biderman (2001).
} 
tronco branco, violência inata, índice cefálico, negro muito preto, servil, apatia, e outras, além de vincular o subdesenvolvimento do Brasil à presença do Negro, tenta promover a teoria do branqueamento, assim como posteriormente faz (LACERDA, 1911) sugerindo ao governo, o incentivo de imigração de brancos, e vaticinando que os negros seriam purgados de seus traços característicos de negro:

[...]graças a este procedimento de redução étnica, é lógico supor que, no espaço de um novo século, os mestiços desaparecerão do Brasil, fato que coincidirá com a extinção paralela da raça negra entre nós. (LACERDA, 1911).

O tempo foi o suficiente para implodir tal prognóstico, e, no que concerne às ideias preconceituosas de (RODRIGUES, 1911), perceba-se que nos relatos de observações do próprio autor, ocorrem frequentes menções de uso de bebidas alcoólicas nos casos degenerescência, como na observação V: [...]mestiça quase branca[...] tem um pai degenerado, alcoólatra; observação XIX: A. J. delírio de alucinação alcoólica...; Observação XXI: com frequência não está sóbrio... surge então o questionamento: seria somente o negro susceptível a degenerescência pelo uso do álcool?

Qualquer ser humano, inclusive os brancos, ricos, graduados, sob maus-tratos, privados dos bens, e padecendo sofrimentos de todos os tipos, reduzidos à escravidão não trariam também as marcas psicológicas degenerativas naturais? Não era a etnia, qualquer que seja ela, que traz propensões à selvageria ou indolência, mas a educação e o meio a qual é submetida.

Ao se recorrer à história e a postulados sobre a origem da etnia negra, seus etnônimos e atuação na civilização antiga, chega-se à ilação de que, a deseducação, o tratamento cruel e a constante depreciação procedentes de diversos formadores de opinião social engendram comportamentos e as ditas taras hereditárias degenerativas, isto é, não se trata de índole imanentemente selvagem, mas produto. Pois no passado a etnia negra exerceu posição de liderança na humanidade.

(DIOP , 1983) fala sobre a origem dos antigos egípcios::

A hipótese da origem monogenética e africana da humanidade suscitada pelo professor Leakey tornou possível colocar em termos totalmente novos a questão do povoamento do Egito. Isso quer dizer que toda a raça humana teve sua origem, exatamente como supunham os antigos... necessariamente, os primeiros homens eram etnicamente homogêneos e negroides. (DIOP, 1983, p.39) (grifo meu)

Em áreas quentes da terra, como nos trópicos, o ser humano se adapta secretando melanina para garantir-lhe menor absorção dos raios solares, e sua pigmentação epidérmica é escura, assim, (ELLIOTSMITH apud DIOP, 1983, p. 41) declara que fica evidente que toda a população egípcia era negra, com exceção de uma infiltração de nômades brancos no período protodinástico.

No que concerne às representações humanas na escrita egípcia, Flinders Petrie revela que a etnia negra era típica. Demonstra que os povos Anu eram negros, sendo representados com emblemas de chefia. Min, uma das importantes divindades do Egito chamava-se "o grande negro". (DIOP, 1983, p. 43).

Além desses dados, (PETRIE, 1939, p. 33) declara: (The mural in tomb SD 63 ( Sequence Date 63) of Hierakompolis shows the native-born blacks subjugating foreign intruders into the valley). $\mathrm{O}$ mural da tumba SD 6 $6_{3}$ ( Sequence Date 63) de Hieracômpolis mostra negros nativos subjugando os invasores estrangeiros.

Heródoto, quando visitou o Egito, descreveu o povo que lá vira, repetindo muitas vezes, que tinham a pele negra: A respeito dos Kolchus, que têm pele negra e cabelos crespos[...] são da raça egípcia.(HERÓDOTO, II, 24). 
Um outro fator que se deve levar em conta são os etnômios. Por exemplo, segundo (MCKSSIC, 1990), Can, um dos filhos de Noé, segundo a Bíblia, (GÊNESIS, 2:13), teve quatro filhos: Cuxe, Mizraim, Pute e Canaã, e teria dado origem às etnias negroides, australoides e mongoloides. De Cush, os cushitas que dariam a origem dos etíopes, sudaneses e núbios, portanto Negros.

Para (MCKISSIC, 1990), Can significa quente, ou negro.; Cush é uma palavra hebraica que significa preto, Etiópia é uma palavra grega que significa homem de face queimada de sol ou preto, de éthios +ops.

Moisés casou-se com uma mulher etíope e era escura. O livro de Jeremias descreve o povo etíope como escuro e alto. (JEREMIAS, 13:23).

Se a hipótese da origem monogenética e africana da humanidade, conforme relato de autoridades em história da África for vislumbrada, então qualquer pensamento de racismo é um atentado contra a própria humanidade.

\section{CONCLUSÃO}

Ao se considerar que a humanidade se constitui de uma raça apenas composta por diversas etnias, bem como o registro histórico das terríveis consequências da insanidade de se supor que uma etnia possa ser imanentemente superior ou inferior a outra, urge compreender que qualquer apologia ou homenagem a tais ideologias racistas devem ser rechaçadas com veemência.

Qualquer ser humano, seja ele de que etnia for, se privado do respeito, da educação, da aceitação social, e do alimento, recebendo por gerações a ênfase de que é inferior, vivendo na privação e sob maus-tratos, não adequados nem mesmo a animais, trará traumas, taras psicológicas e físicas degenerativas.
É possível entender que nomear um lugar é ato intimamente interligado à tomada de posse e à caracterização do lugar que lhe concede alma e fisionomia reflexa ao nome dado. Decorre daí que a outorga de nome faz inexoravelmente referências à entidade por ele designada.

Em meio às teorias da Frenologia, Darwinismo Social e Eugenia que permeavam as mentalidades e os paradigmas do século XIX, somadas à importação negreira para escravidão, e posterior à derrocada da revolta popular conhecida como Balaiada, que teve como um de seus líderes um ex-escravo negro, nasce Raimundo Nina Rodrigues.

Naturalmente, o Dr. Raimundo Nina Rodrigues foi imbuído de conceitos racistas e discriminatórios, que o faziam crer na degenerescência humana por meio da mestiçagem.

As obras de Nina Rodrigues apresentam-no convicto de que supostamente a raça branca era superior à negra que, para ele, padecia de tara degenerativa. $\mathrm{O}$ município onde nascera é elevado à categoria de município, após ter sido desmembrado de Vargem Grande, pela lei n. 2183 de 30 de Dezembro de 1961 e é denominado de Nina Rodrigues no estado do Maranhão.

Levando-se em conta que, o ato de nomear não encerra apenas uma intenção identificatória, mas de tomada de posse e perpetuação da fisionomia refletida do homenagiado, o município de Nina Rodrigues pode estar advogando o mito da degenerescência pela mestiçagem, da superioridade de uma etnia sobre outra, bem como o racismo, porque, como afirma (CARVALHINHOS, 2002/2003, p.172):

Os estudos onomásticos resgatam a história social contida nos nomes de uma determinada região para tratar um panorama motivacional da região e a ideologia do denominador. 
Os indivíduos são seres responsáveis por sua formação e juízos de valor a despeito do espírito da época no que diz respeito à resignificação dos costumes por meio do pensamento emergente.

Dessa forma, após se analisarem as declarações de condescendência para com a eugenia, branqueamento, frenologia e sobrevivência do mais forte oriundas de Raimundo Nina Rodrigues, chegase à ilação de que, a despeito da notoriedade e glamour trazidos ao estado de seu nascimento, qualquer apologia ao racismo, mesmo que subreptícia como a homenagem toponímica a Nina Rodrigues, é inconcebível tanto quanto denominar uma cidade de Hitlerópolis apenas porque Adolf Hitler pintou um quadro e cursou a faculdade de belas artes.

\section{AGRADECIMENTO}

Agradeço a Deus, em quem todas as coisas subsistem. À Profa. Dra. Karylleila Andrade pelas excelentes aulas e instruções. E a minha família, Olívia, Christopher e Kelvin.

Todos os autores declararam não haver qualquer potencial conflito de interesses referente a este artigo.

\section{REFERÊNCIAS}

AYROSA, PLÍNIO. Têrmos Tupís no Português do Brasil. São Paulo: Revista dos Tribunais, 1937. BAKTHIN, MIKHAIL. Estética da Criação Verbal. 3. ed. São Paulo: Martins Fontes, 2000.

BIDEMAN, M.T.C. Teoria Linguística: Teoria Lexical e linguagem Computacional. $2^{\mathrm{a}}$. ed. Martins Fontes: São Paulo, 2001.

BOURDIEU, PIERRE. A Economia das Trocas Simbólicas. 2. ed. São Paulo: Perspectiva, 2005.

A Dominação Masculina. Rio de Janeiro: Bertrand Brasil, 1999.

BUENO. M. A Origem Curiosa das Palavras e/ou dos Significados. Rio de Janeiro: José olympio Ed. 2003.
CARVALHINHOS, PATRÍCIA DE JESUS. Onomástica e lexicologia: o léxico toponímico como catalizador e fundo de memória. Estudo de Caso: os sociotopônimos de Aveiro (Portugal). In.: Revista USP. São Paulo, n.56, p.172-179, 2002-2003.

CARVALHINHOS, PATRÍCIA DE JESUS. 2016. Disponível em: http://toponimia.fflch.usp.br/node/8 acessado em 10.set.2016, 13h.

CLAEYS, GREGORY. A Sobrevivência do mais apto e a Origem do Darwinismo Social - Revista de História das Ideias 61(2): 223-240, 2000. Disponível em:

http://www.historia.uff.br/nec/documentos/revolucaoindustrial. Acesso em 19/set/2016.

CLOVAL, Paul. A Geografia Cultural, 2a . ed. Florianópolis: EduFSC, 2001.

CORREA, MARIZA. As Ilusões da liberdade: a escola de Nina Rodrigues e a Antropologia no Brasil. Braganca Paulista: Edusp; editora da Universidade de São Francisco. 1998-2001.

DICK, MARIA VICENTINA DE PAULA DO AMARAL. "Toponímia e Cultura", in: Rev. Inst. Est. Bras., SP,27:93-101, 1987

DICK, MARIA VICENTINA DE PAULA DO AMARAL. Toponímia E Antroponímia No Brasil. Coletânea de Estudos. 2. ed. São Paulo: FFLCH/USP, 1990.

DURKHEIM, EMILE. As Formas Elementares da Vida Religiosa. São Paulo: Abril

Cultural, 1978.

ERWIN, RAISZ. Lettering and geographical names' general cartography. N.Y. London: McGraw-Hill, 1948.

FRANK, JOSEPH. DOSTOIEVSKI. 1850-1859 - Os Anos De Provação. Tradução de Vera Ferreira. São Paulo: Edusp, 1999.

FURTADO, SEBASTIÃO DA SILVA, MAJ. A Toponímia e a Cartografia. Rio de Janeiro: Ministério da Guerra, 1960.

GIRARDI, GIOVANA (fevereiro de 2007). «Qual é a origem dos nomes dos Estados brasileiros?». In https://pt.wikipedia.org/wiki/Etimologia_dos_nomes_ das_unidades_federativas_do_Brasil\#cite_note-

galileu-2 Consultado em 15 de maio de 2016.

HERÓDOTO. Histories livro II, Texto org. e trad. Por P.-E. Legrand (1932-1954). Paris, Coll. Des Universités de France. 2 vol. (2).

HOUAISS, ANTÔNIO. Dicionário Houass de Língua Portuguesa. Rio de Janeiro: 2004.

JACKSON. JOHN GLOVER. Ethiopia and the Origin of Civilization, (1939). Disponível em: http://www.archive.org/details/EthiopiaAndTheOrigi nOfCivilization

JANOTTI, AMARO E LOURDES, MÔNACO. A Balaiada. São Paulo: Brasiliense, 1987.

LACERDA, JOÃO BATISTA. Sobre os Mestiços no Brasil. Tradução de Eduardo Dimitrov, Íris 
Morais Araújo e Rafaela de Andrade Deiab do artigo sur le métis au Brésil, publicado em Premier Congrès Universel des Races: 26-29 juillet 1911. Paris Imprimérie Devouge. 1911.

MARCUSCHI, LUIS ANTONIO. Do Código para a Cognição: O Processo Referencial Como Atividade Criativa. Revista Veredas. Minas Gerais, vol. 6 N. 1, p. 43-69.

.Cognição e Linguagem: Praticas Interacionais. Rio de Janeiro: Lucerna,

2007.

Mayr, E. The Growth Of Biological Thought:

Diversity, Evolution And Inheritage. Cambridge-

Harward UN press. 1982.

MCKISSIC, WILLIAM DWIGHT. Beyond Roots:

In Search of Blacks in the Bible Paperback - June, 1990.

MOORE, R. A Evolução. Rio de Janeiro: José Olímpio. 1970.

MORIN, EDGARD. Por uma Reforma do Pensamento. Tradução de Ribas, M.C. conferência introdutória ao colóquio "reforme de la penseé et système educatif", promovido pela Unesco, Paris, set, 1994.

NASH, JOSHUA. Insular Toponymies. Placenaming on Norfolk Island, South Pacific and Dudley Peninsula, Kangaroo Island. Amsterdam, Netherlands: John Benjamins Publishing Co., 2013.

NEIVA, ARTHUR HEHL. Povoamento do Brasil No Século XVIII. São Paulo: Indústria Gráfica, 1952.

PETRIE , W. M. F. The Making of Egypt. London. 1939, p. 67

RODRIGUES, RAIMUNDO NINA. Os mestiços Brasileiros. Gazeta médica da Bahia, 21 (9): 401407; 497-503, 1890.

RODRIGUES, R. NINA. Mestiçagem, degenerescência, e crime. Tradução de Mariza Corrêa do artigo "Métissage, dégénerescence et crime", publicado nos Archives d'Anthropologie Criminelle, v.14, n.83, 1899. O exemplar usado para esta tradução, cópia do existente na Faculdade de Medicina da Bahia, trazia uma dedicatória em francês, manuscrita, para Alfredo Britto, na qual só é legível a palavra amitié, assinada por Nina Rodrigues e com a data de 10 de janeiro de 1900. Abaixo, a informação sobre a editora: Lyon, A. Storck \& Cie, Imprimeurs-Éditeurs.

SANTOS, MARIA VILLELA. A Balaiada e a Insurreição dos Escravos no Maranhão. São Paulo: Ática, 1983.

SCHNERB, R., tomo VI - in História Geral das Civilizações, vol.XIV, DIFEL, 1961, pág. 233

SIMPSON, GEORGE GAYLORD. The major features in evolution. Nova York: Columbia University Press, 1953. p. 96.

SKIDMORE, THOMAS ELLIOT. Preto no branco. Raça e Nacionalidade no Pensamento Brasileiro. $2^{a}$. ed. Trad. R.S. Barbosa. Rio de janeiro. Paz e terra, 1989 (col estudos brasileiros, vol.9).

STEFANO, WALDIR. Octavio Domingues e a Eugenia no Brasil: Uma perspectiva 'mendeliana'. São Paulo, 2001. Dissertação (mestrado em história da Ciência) - Pontifícia Universidade Católica de São Paulo.

TIBIRIÇÁ, LUÍS CALDAS. Dicionário de topônimos Brasileiros de origem Tupi: Significado dos nomes geográficos de origem tupi. Brasil. Traço, 1985.

VASCONCELOS, J. LEITE DE. Opusculus, Vol III Onomatologia. Coimbra: Imprensa da Universidade. 1931.

VIEIRA FILHO, DOMINGOS. Breve História das

Ruas e Praças de São Luís. Editora: Gráfica Olimpica. 1971.

WILLIAMS, RAYMOND. Darwinismo Social na Avaliação crítica de Helbert Spencer. John oferta. ed. P. 186-199, 2000.

WILLIAM, E. Marxismo e literatura. 1979.

WHITE, Ellen, Review and Herald, June 6, 1893.

Review and Herald, June 6, 1893.

Carta para E. J. Waggoner, 22 de Janeiro de 1893,

Carta 78, 1893, EGWE. 